of the eye ball. The injury was followed by a punched-out hole with a red base in the macular region.

One of his cases is of importance because the observer saw the patient immediately following the injury, at which time the macular region was opaque and the veins tortuous and full. In about three weeks this condition changed to a typical hole at the macula.

R. Foster Moore ${ }^{7}$ (1910) reported a case of concussion of the eye ball the ophthalmoscopic examination of which showed a hole in the macula $11 / 3$ the size of the optic nerve head. The opposite side showed a similar condition, but there was the appearance of bright red holes with shelving edges and many whitish areas of all sizes scattered about this region.

A. C. Clapp" (1913) reported a case of macular hole following a contusion in which there were numerous deposits of cholesterin crystals in the vitreous as well as the fundus.

Zentmayer in 1909 and de Schweinitz ${ }^{10}$ in 1904 reported cases of macular hole of nontraumatic origin. The lesion has also been observed following postoperative iridocyclitis.

Whether or not the lesion as described in this case report was caused by an injury, or is the result of some inflammatory process, it is impossible to ascertain on account of the uncertain history furnished by the patient.

\title{
BIBLIOGRAPHY.
}

1. Knapp, H. Archiv für Augenh. u. Ohrenheilk, v. 1, p. 22, 1869.

2. Noyes, H. D. Trans. Amer. Ophth. Soc., 1871, p. 128.

3. Fuchs, E. Zeit. f. Augenh. v. 6. 1901, p. 161. Graefe's Arch. f. Ophth. v. 79, 1911, p. 42.

4. Coats, G. Royal London Ophth. Hosp. Reports, v. 17, 1908, p. 69.

5. v. Hippel, E. Graefe's Arch. f. Ophth. v. 64, 1906, p. 172.

6. Twietmeyer. Zeit. f. Augenh. v. 18 , p. 447.

7. Moore, R. F. Trans. Ophth. Soc. United Kingdom, v. 30, 1910, p. 155.

8. Clapp, A. C. Ophth. Rec. v. 22, 1913, p. 79.

9. Zentmayer, W. Ann. of Ophth. v. 18, 1909, p. 472.

10. de Schweinitz, G. E. Trans. Amer. Ophth. Soc. v. 10, 1904, 228.

\section{GLAUCOMA FROM THE ABSORPTION OF SENILE CATARACT.}

\author{
Harold Gifrokd, M. D., F. A. C. S. \\ OMAHA, NEB.
}

A paper discussing the relations between these two conditions and reporting four additional cases of such sequence, read before the Third Colorado Ophthalmological Congress, August 10th, 1917, with discussion.

The spontaneous cure of senile cataract is by no means so rare as is commonly supposed, or as would be inferred from the statement of Hess, in the last edition of the Saemisch Handbook, that to date, over sixty cases of this sort have been reported. I have seen ten cases in which practically complete absorption of the cortex has occurred. In three of these, useful sight was obtained $V=20 / 70,20 / 100$ and $20 / 200$ respectively. In six others the conditions would have allowed useful vision if they had not been compli- cated with glaucoma. This tendency for senile cataracts to undergo spontaneous absorption is so common that I think it may safely be said that while every one would develop a senile cataract if he lived long enough; so also would every one obtain a spontaneous cure, if life were sufficiently prolonged. Unfortunately, nature's method of cure does not give a good percentage of visual results. The frequency with which glaucoma is associated with the absorption of senile cataract has been noted by Mitvalsky ${ }^{1}$ and Reuss ${ }^{2}$, and 
more recently by Verrey $^{3}$; but these writers have concluded that the glaucoma or some inflammatory complications are the cause of the absorption of the lens, while in my opinion the case is the other way around. I believe that the spontaneous absorption of the cortex of a senile cataract produces, in many cases, an increase of tension which may be temporary and unnoticed; or which may lead to complete blindness; in which case the absorption of the lens is commonly attributed to the influence of the glaucoma. In my previous paper, in which I reported four cases of spontaneous cure of cataract, out of which three were complicated with glaucoma, I based my belief on the fact that in two of the cases the eye had been seen with a mature cataract without any signs of glaucoma some time before the absorption of the lens, and that after the absorption of the lens and the onset of the glancoma, the other eye had been followed from two to seven years without the appearance of any signs of glaucoma.

Since that time I have seen four other cases of spontaneous cataract absorption associated with glaucoma; and from the continued observation of some of my previous cases I can give decidedly more positive proof of the dependence of the glaucoma on the absorption of the cataract.

In one of my previously reported cases, Case 1, a man of sixty-three had a preparatory iridectomy done on the left eye for an uncomplicated immature cataract. The patient returned after five years, with the left eye absolutely blind from glaucoma, with the lens all absorbed except a small brown nucleus. I followed this man for twenty years, at the end of which time a cataract matured in the other eye, and was expressed with a good result, without any signs of glaucoma having developed. Another patient of this old series, Case 2 , who at the time of the report, had a spontaneous cure of cataract, with vision of $20 / 70$, later developed glaucoma on account of the nucleus getting into the anterior chamber, and was cured by an extraction. This case should of course, be placed in a different class from those in which the glaucoma is the direct result of the absorption of the lens without any dislocation.

In a third of these older cases, Case 3 , a woman of sixty-five years, with nearly mature uncomplicated cataract, reported again after two years, with the cortex absorbed, a small nucleus sunk down so as to leave the upper third of the pupil free and the eye $a b-$ solutely blind from glaucoma. The other eye had had a cataract removed ten years before with resulting vision of 20/50 and no signs of glaucoma in that eye; nor did any such signs appear in the next few years during which $I$ kept track of her.

In some of my more recent cases I have an almost continuous record of the conditions before, during and after the occurrence of the glaucoma and the absorption of the lens.

Case IV, F. J. T., male, 47 years, seen first 3-29-1911. Right eye, mature cataract; $V=$ hand movements three feet, good projection. Left eye, slight lens opacities, $V=20 / 15$ After about three years, this patient was seen again and although the right lens, with undilated pupil, showed no decided change, its projection was found to be so poor that patient was advised that an operation would probably not be worth while. There was nothing unusual about the appearance of the eye and the tension was not tried at this time. In 1915 the tension became decidedly high $(59 \mathrm{~mm}$.), with considerable pain and congestion. A trephining was done with some reduction in tension and disappearance of the pain and congestion. On 5-27-16 the tension was still high $(51 \mathrm{~mm}$.) and it was plain that the lens was undergoing absorption; most of the cortex was absorbed and the iris was tremulous: Extraction and iridectomy were advised, but the case has not been seen since then. During the five years period of observation the other eye retained vision of 20/15 with absolutely no sign of glaucoma. I realize that this case could be quoted on either side of the question, but if the cataract had been examined with a dilated pupil when the projection was first found to be bad I 
believe that signs of beginning absorption of the cortex would have been detected; and that the increased tension was the result of the contintuation of this process.

The same remarks apply to

Case V, woman 54 , seen by my colleague, Dr. Patton, on 6-25-1915. Right eye, cataract of some years standing, tension 51, cornea steamy, exact condition of cataract not ascertainable. $V$. not noted but very. poor. Posterior sclerotomy was done and patient was not seen again until 5-31-16. She returned with an acute iritis in the right eye and was given atropin; a few days later I found the pupil dilated enough to show that the cortex of the lens had been absorbed and the small nucleus was low lown in the posterior chamber. Later on it appeared in the anterior chamber and was removed with the loop, on account of persistent symptoms of irritation, although the tension had sunk to normal or thereabout. The eye was blind. The other eye had had a cataract removed from it eight or ten years previously and in 1917 showed vision of $20 / 30+$ with no signs of glaucoma.

Case VI, male 69, first seen 6-15-14. Right eye, old milky looking cataract; projection poor; divergent strabismus. 'The projection of this eye was so poor that it was not cleemed best to operate on it and as the left eye, in addition to cataract had dacryocystitis and ectropion of the lower lid, the sac was destroyed, the ectropion cured and after some months the lens expressed with a good result. While at the hospital, the blind right eye got painful and hard. A trephining was done but the hole was made too far back and the iris did not prolapse. The cyc became painless but still had some tension on his return to his home in Montana. For the subsequent history of the case I am indebted to his home oculist, Dr. W. A. Walters of Billings, Montana, who wrote me that soon after he reached home he developed what seemed to be an irido-cyclitis in the right eyc with some precipitation in the anterior chamber; high tension and steamy cornea. When the acute symp- toms subsided, after a few weeks, the tension became normal, the sight began to improve, the cortex of the lens was found to be practically all absorbed, with a sunken nucleus; and the eye had vision of about 20/200 which has been maintained without any further increase of tension. The left eye continues good with no signs of glaucoma.

Case VII, male, operated by me for senile cataract of the left eye in 1906, at the age of 56; resulting vision $20 / 20+$. The right eye became slowly blind from developing cataract in the course of the ensuing years but I did not see him again until 5-22-17 when he returned stating that on the day previous, the right eye (the unoperated one) suddenly became very painful and congested with diminution of what little sight he had previously had. I found the left eye to be still in perfect condition; $\mathrm{V}=20 / 20+$ with correction. The right eye was deeply congested, the conjunctiva slightly edematous, anterior chamber deep with greyish deposit at bottom, cornea hazy, pupil small, lens opaque, $\mathrm{T}+2 . \mathrm{V}=$ light perception, no projection. The symptoms in this case were so violent that my first impression was that the eye had a beginning metastatic panophthalmitis, and the man was put on atropin, hot applications, inunctions of mercury and salicylat; and a corneal paracentesis was made twice a day for two days. At the end of this time all serious symptoms had disappeared, tension was normal, pupil moderately dilated, cornea and aqueous clear. It could now be seen that all the cortex except a little in the center had disappeared leaving the brown nucleus low down in the posterior chamber. The projection was good and two months later, during which time the eye had been perfectly comfortable. I made a forceps extraction of the nucleus in the capsule which gave him vision of $20 / 70$ with correction, at the first test. There were a number of fine opacities in the vitreous, but no signs of glaucoma.

Keeping in mind the common symptoms of the last two cases, i. e., old 
cataract, a sudden onset of tension with inflammatory symptoms; grey deposit in the anterior chamber, disappearance of the latter and restoration of useful sight with or without operation, I think it is fair to assume that a similar sequence has occurred in many if not all of the cases in which the combination of glaucoma with cataract cortex absorption has been observed. In some cases the absorption of the cortex seems to produce no increased tension. In many of these, however, where the cortex is absorbed or discharged into the anterior chamber a little at a time, it is probable that a transient increase of tension occurs but attracts no notice on account of the blindness from the cataract and the lack of pain. When the cortex escapes into the anterior chamber in any quantity, it seems to excite a decided chemotaxis, and where with irido-cyclitic symptoms, any of this cortex is seen in the chamber, it is natural to take it for inflammatory exudate. Whether the increased tension is due to direct blocking of the outlets by the cortex or is the result of the chemotaxis, or both, it is very difficult to decide; but I think there can be no doubt that the impression which some authors have gained that the spontaneous absorption of cataract is due to the occurrence of irido-cyclitis is based upon a misinterpretation of the congestive symptoms which accompany the absorption of the cortex, and is as erroneous as the belief that the absorption depends upon the occurrence of glaucoma.*

The foregoing facts and conclusions may throw some light on the somewhat mysterious loss of sight which is said to occur in so many eyes in which the lens has been couched. The report is that such eyes nearly always go blind from irido-cyclitis or glaucoma even when they are operated aseptically; and it seems to me much more reasonable to suppose that these results instead of being due to the bouncing about of the lens upon the ciliary processes are due to the chemotaxis or the increased tension which the absorption of cataractous lens matter apparently produces.

An interesting question is: What is the subsequent fate of eyes that have successfully passed the first danger of glaucoma from the spontaneous cure of cataract. We know that they are open to the danger of glaucoma from dislocation of the loose nucleus into the aniterior chamber as shown in Case I; but there is also a question as to whether some harm may not result from the gradual breaking down and absorption of the nucleus. I have seen two cases of men about forty years of age with a hard nucleus in the anterior chamber, where there have been periodic attacks of intense pain, congestion and increased tension, with such complete absence of any trouble in the interim, that I have obtained the impression that these attacks were due to the sudden breaking down of the outer shell of the nucleus which, in the quiet periods, has been slowly prepared for the change.

It will doubtless be asked, why if hypermature cataracts are capable of causing such effects, we do not see more of the same sort of thing after the needling of soft cataracts; for after the initial glaucoma due to swelling of the lens and the release of debris which so frequently follow the first needling, the further process of absorption proceeds uneventfully. To explain this clifference wc must, for the present, appeal to the mechanical and chemical peculiarities of the hypermature cataract of adults. It may be the process is akin to the glaucoma which accompanies essential atrophy of the iris, $i$. e., the glaucoma in the latter class of cases may be due to the products of iris disintegration.

- Since the above was written I have noticed the report by Schwenk in Oph. Record, Sept. 1917, p. 465 , of a case of glaucoma from what he calls hyperreactive cataract. He has seen two other cases of the same sort and his views as to the production of glaucoma and inflammatory symptoms by a disintegrating senile cataract correspond entirely with my own. 


\section{CONCLUSION.}

The occurrence of glaucoma coincident with the absorption of hypermature cataract cortex in eyes otherwise healthy, together with the long continued absence of glaucoma from the fellow eye, makes it probable that the glaucoma which has been observed in connection with the spontaneous absorption of senile cataract is the effect, not the cause of such absorption. It follows that a senile cataract should be kept under observation and operated before it becomes too hypermature, even if the other eye still has good sight.

\section{DISCUSSION.}

Marcus Feingold, New Orleans, said: About seven years ago I reported three similar cases, the report not being printed through my own fault. The picture was very much alike in all three instances, that of an acute attack of glaucoma; but the eyes showed deep anterior chambers. The aqueous was cloudy in all, and in onc instance even a small hypopyon was present. The iris was discolored in all and tremulous in two cases. This, together with the milky, uniform capacity of the lens and the marked incrcased tension, helped in making the diagnosis. Speedy relief was had in all three cases by the cxtraction of the overripe cataract with resulting good vision. At the time of my report search of text- and hand. books failed to reveal any warning not to allow a cataract to become overripe, becausc it might result in an attack of glaucoma. As to the cause, irritation of the ciliary body by the subluxated, because shrunken, lens seems to be the only plausible explanation.

Edward Jackson, Denver, said that last year he had seen a case in a woman who had suffered from double cataract sixteen years before. One eye had been operated upon, the other left to nature. He. saw her two months before her attack of glaucoma. In the eye which had not been operated he found the iris tremulous and a Morgagnian cataract. She was given her correction for this eye with the hypernature cataract. But she came back in two months with an elevated tension. Miotics were of very little value. Atropin was very much-better. She had a distinct irido-cyclitis.

Melville Black, Denver, said this danger of setting up glaucoma might point to the operative indications in such cases. He had seen three cases in which the second eye became cataractous later, with a good result in the first or operated eye. We should operate both eyes, he believed, and not let the second eye alone. Thus we could avoid letting the patient have a Morgagnian cataract with the evil consequences of a secondary glaucoma.

Harold Gifford (closing): We should watch these cases very carefully. We should operate the first eye, unless the patient is willing to take the responsibility of being sure that the second eye will last as long as he lives. Dr. Jackson's case developed glaucoma suddenly. Dr. Gifford believed that degeneration of the cortex did not necessarily produce the glaucoma. On the other hand, he could not agree with $\mathrm{Dr}$. Feingold regarding the importance of traction on the ciliary body in producing the glaucoma. In one of Dr. Gifford's cases, the anterior chamber was deep and the iris pushed back. The nucleus was not causiny any trouble. He did not believe the nucleus irritated the ciliary bodv, but he did believe that the toxicity of the lens cortex was a bigger factor. He expressed the opinion that the theory as to traction upon or irritation of the ciliary body had always sounded rather "fishy" to him in these cases. The pain comes on very suddenly and the eye is very red. A paracentesis gives relief quickly. He believed that the cortex probably undergoes degencration and the toxic products absorbed from the lens produce the glaucoma.

1. Mitvalsky. Centralblatt f. p. Augenheilkunde, Oct. 1892, 297.

2. Reuss, ibid., Feb. 1900, 39.

3. Verrey, abst. in Annals of Oph., Oct. 1916, 802.

4. Gifford, Anerican Journal of Oph., Oct. 1900. 